compared with previous labours. He attributes this to the absence of the child, and to the small quantity of the milk. That these were some of the causes of the abwence of pains cannot be denied, but I should suppose that, in this case of abortion, there was a worn-out constitution, incapable of producing the salutary action on the uterus, unassisted, also, by the stimulating effects which are produced by the child. But what is the consequence in such a case as this? the uterus remains for ever uncontracted, or until the mother is again pregnant, laying the foundation of uterine diseases, the secondary cause of which may be cold; these complaints are not unfrequently stationary till after the cessation of the menses, then ending fatally in the course of a few years the origin of which, in almost every instance, may be easily traced to neglect and mismanagement of the uterus during the first two or three days after confinement, and above all, to the use of opiates. In cases of abortion, a hired child, if one cannot be procured otherwise, ought to be applied for a few days ; it would assist in the contraction of the womb, and, I am satisfied, be the means of preserving many a valuable life which is taken from the family circle, in the prime of life, when most wanted. The following observation of Mr. Smith's I think most aangerous. He says, if a child is not applied to the breast so early as usual in labours subsequent to the first, the after-pains are, according to his experience, considerably diminished in intensity and duration. No doubt they are so. But what is the effect upon the uterus? It is uncontracted, never comes to its natural size, the mouth never reduced to less than half an inch in diameter. Then follows hysteralgia, strangury, procidentia ateri, \&c., laying the foundation also, in after-life, of other lingering, painful, and incurable diseases. Opiates, for such purposes as Mr. Smith uses them, either external or internal, I consider to be most destructive to the state of the patient's health. Whenever you have after-pains (and the sooner they appear the better), encourage them, by gently tightening the bandage and applying the child to the breast; such pains are doing good somewhere; I have never seen bad effects arising from them, even although continued for weeks ; the patient has always some intervals of ease, sufficient to procure short refreshing sleeps. For years it has been my invariable practice, unless in cases of extreme exhaustion, to put the child to the breast the moment it is dressed; and I always find good comes to the mother and child from such practice. The child never sucks so neatly or well after it gets the spoon; and the difficulties in getting it to $f x$ after I need not here enumerate. It is a gross and vulgar error, that there is no nourishment to a child for two or three days after it comes into the world. I have nursed and brought up children, from the middle of the eighth month, with the mother's milk alone; it will suck with ease, even at that age, where there is a good nipple, and when not at first spoiled with spoon-meat. The uterus contracts thoroughly, because done early; the meconium is carried off without medicine; the child sucks for perhaps half an hour, and, if kept warm, beside the mother, leeps for the next twelve; and besides, I can leave the mother instantly, without fear of uterine hæmorrhage.

In such cases the lower animals might learn us many a lesson; I have seen a puppy sucking its mother before it was fully into the world; and not unfrequently, when the was engaged in lacerating the umbilical cord.

Mr. Smith's concluding remark is most erroneous. In women, he says, who have had several children, the infant is generally applied to the breast too soon, and that it is the cause of the severity of the after-pains. No doubt it is a cause, and a most salutary one it is ; and $I$ thall only add, when done early, effectually, and persevered in, will prevent more than nineteen-twentieths of the uterine diseases which females are subject to in the decline of life.

Aberdeen, May 1, 1811.

"IN inflammations, however originating, whether from injury or diseased habit, affecting the extremities, general bloodletting is seldom advisable, or even practicable with safety. From the part blood is taken, by various methods, with very great advantage in such cases."-Tracers.
MALPOSITION OF THE AORTA AND ITS CHIEF THORACIC BRANCHES.

By George S. Brent, Esq.

IN the dissecting-room at University College I have been, lately, a witness to a remarkable abnormal distribution of the arteries arising from the arch of the aorta. The aorta itself was, in this instance, so far transposed from its usual position that its arch proceeded from left to right, instead of from the right to the left side of the median line,- originating from the heart nearly opposite the junction of the fourth left rib with its cartilage, and proceeding thence upwards, backwards, and towards the right, to reach the left side of the vertebral column, along which, as customary, the remainder of the vessel descended. From the ascending portion of the arch were given off, first, the right carotid artery, which crossed the thorax behind the first bone of the sternum to attain the right side of the trachea, \&c.; next, the left carotid, which at first sight appeared to issue by a trunk common to it and its predecessor, though further examination proved this not to be the case; this branch proceeded nearly straight upwards to its destination : thirdly, arose the subclavian, a larger branch than either of the foregoing, immediately after which it was given off; it ascended at once to about the level of the summit of the first dorsal vertebra, and descended again as abruptly to pass towards the axilla, forming what may be expressively, if not correctly, termed an " acute arch." All these arteries arose from the ascending aorta; fourthly, at about an in $2 h$ distant from the last named branch, the right subclavian originated a little beyond the culminating portion of the aortic arch by a bulbous enlargement in close apposition with the body of the third dorsal vertebra. It ascended perpendicularly (still on the left side of the body) to the level of the seventh cervical vertebra, before it assumed its lateral course across the neck, - in which course it passed over the vertebral column behind the trachea and oesophagus. The subject in which these anomalies occurred was deformed; the two sides of the thorax were unequally developed, the spinal column presenting a considerable curvature to the right side. The production of such a curvature in childhood or afterlife, and the consequent malposition of the heart, might possibly have proved adequate to account for the altered position of the arch of the aorta; but the unusual length of the right carotid and right subclavian arteries (necessary to enable them to reach their destinations) leads inevitably to the belief that the abnormal distribution of the arteries, together with the deformity, was wholly congenital; and this derives confirmation from the circumstance that in the case in question the recurrent laryngeal nerve of the right side curved around no artery, but proceeded at an angle from the pneumogastric nerve directly to its distribution on the larynx. I learn that this abnormal specimen is to be placed in the museum of the college.

I am well aware that variations in the origin and position of the arteries are matters of such frequent occurrence as commonly to demand little especial notice; but the instance above cited has appeared to me sufficiently sui geweris for a record of it to deserve insertion in your columns. Since observing it, I have carefully examined the plates of both Tiedemann and Quain, bearing reference to variations in the origin of the great arteries arising from the aortic arch, yet no single example there delineated bears an exact similitude to that which I have described. In many instances both carotids are found coming off before the subclavians; and in Tiedemann's Tab. ii., fig. 8, they are seen thus coming off together as branches of a very short, common trunk. Several examples have been displayed of the right subclavian artery given off last of the four, and passing behind the oesophagus ; and Quain's Tab. vii., fig. I, shows the aortic arch in a reversed position, accompanied by anomalies in its branches. But in none of the instances presented in the copious collections of such anomalies in the above works have I noticed the extensive perpendicular ascent of both subclavians, or the origin of three of its four great branches from so early a portion of the arch of the aorta; nor have I found any such unusual eondition of the recurrent nerve 
cited in the text, as obtained in the case which forms the basis of these few observations.

I subjoin two delineations of the appearance of the aortic arch and its branches in this instance, -one as seen in situ from the front, and the other as observed on looking at it from the left side, which may help to render my description the more readily intelligible.

Fig. 1 .

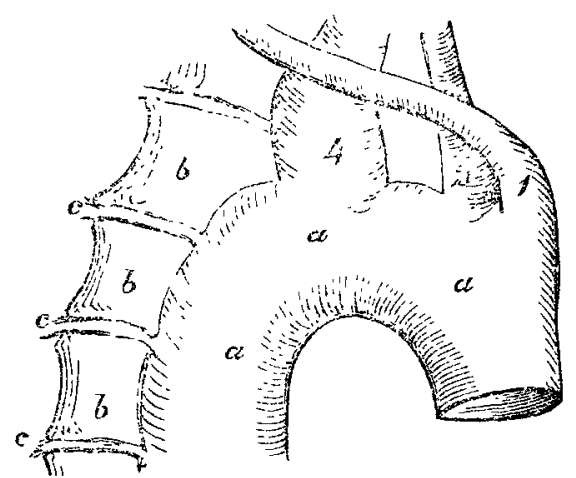

Fig. 2.

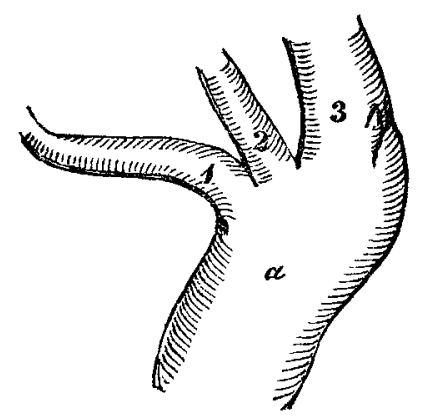

Fig. 1. The Aortic Arch, \&c., as seenfrom the Front.

a. Arch of the aorta.

b. Bodies of the dorsal vertebræ.

c. Intereostal arteries.

1. The right carotid artery.

2. Left carotid artery.

4. Right subclavian artery.

(The left subclavian is in this figure conceale by the left carotid artery, behind which it arises.)

Fig. 2. The Aortic Arch, \&c., as seen from the Left Side. a. Ascending aorta.

1. Right carotid artery.

2. Left carotid artery.

3. Left subclavian artery.

\section{PRACTICAL OBSERVATIONS.}

By John Chippendale, Esq.

I Fivs that in a short notice which I addressed to you on the subject of idiopathic erysipelas, $\mathrm{I}$ neglected to say, that of the mixture of infusion of senna and decoction of cinchona which I recommended, and which should be made in such proportions as to produce eight ounces, one ounce is a dose.

As I believe you are always the best pleased when the communications of your correspondents are of a practical nature, I will avail myself of this opportunity of conveying a few observations of that kind to you, trusting they may be of use to some of your readers.

In your publication of this day I find a note from Dr. Allnatt respecting the "Best Remedies for Neuralgia." Conversing, some short time ago, with a professional friend on the sulject of this disease, he told me that he had found considerable advantage to accrue, after everything else had failed, from frictions with a strong infusion of tobacco, to which he adds the potassio-tartrate of antimony. These appear to me to be so opposite in their nature that I should scarcely think of employing them in conjunction; but I have tried the infusion of tobacco in two cases, and have, in both of them, met with complete success. It appears to me that an extract might be prepared from the tobacco, which, being mixed with simple cerate, would be a more convenient form for frictions.

One of your correspondents, Mr. M. K. O'Shea, in speaking of fractures of the bones of the forearm, advocates the prone position of the limb when the fracture is put up. He will find that doctrine inculcated in $\mathbf{M r}$. Lonsdale's excellent "Treatise on Fractures," which (I speak from memory, not having the book by me) must have been published some five or six years. There is, however, another important point which, Mr. O'Shea has not mentioned, which is, that a wedge-shaped pad should be placed between the bones, to counteract the efforts of the pronator quadratus muscle.

I will close with a practical remark on catheterism. Sir Astley Cooper says that when it is desired to introduce a catheter into the bladder during the existence of enlargement of the prostate gland, an instrument of elastic gum may be selected, which being introduced as far as to the obstruction caused by the enlarged gland, the stilette may be partially withdrawn, by which process the point of the catheter will be raised, and may then be pushed on into the bladder. This is a very useful hint, but I would beg to add to this a caution to junior practitioners, to the effect that the stilette having been thus partially withdrawn, there should not be any attempt made to return it whilst the instrument remains in the passage ; for if the gland is only laterally enlarged the point of the catheter may be so diverted from the straight line that the eye may allow the stilette to pass outside, and thus lacerate the parts. This happened to me some years ago, although the result was fortunate, for, by this manœurre, an abscess, of which I did not even suspect the existence, was punctured, a large quantity of pus was discharged, and my patient recovered; so that I acquired a share of glory which did not really belong to me. But it is not every case which might terminate thus fortunately.

Great Queen-street, April 6, 1844.

\section{MIDWIFERY REPORT.}

DURATION OF LABOUR AND LENGTH OF THE FUNIS.

By G. Y. Hunter, Esq., Surgeon, Margate.

In my letter which you inserted in THE Lancer of the 5th of Nov., 18.12, I promised to send you the result of my continued investigation connected with the above subject, and, therefore, I now forward a table of 123 midwifery cases, in which $I$ have been able to measure the funis. You will see that in some instances I have added the age of the parents, in hopes of aiding the inquiry which has been commenced by the German writers, for the purpose of ascertaining how far the sex of the infant depends upon the father's age; a question which might soon be set at rest if the registrar-general could be induced to direct the district-registrars in England and Wales to insert, in the proper column of each book of births, the age of the father and mother, whenever it could be obtained. As I have also, in the accompanying report, noticed the deviations from nature, it may be considered as an appendix to the table of 2250 cases published at page 537 of THE LANCET, of January 7 th, 1843. In conclusion, I shall briefy observe that in my opinion neither the great length nor extreme shortness of the funis is likely either to expedite or retard delivery, at least, when the contraction of the uterus is strong enough to expel the foetus, it being clear to me that a very short funis would be soon torn from the placenta, as in case uumbered nine (an event which I have known to happen before), or the placenta ejected along with the child, which I have often seen occur in labours where the pregnancy had advanced as far as the seventh month. If $\mathbf{m y}$ life should be prolonged to the close of the year, I hope again to transmit you the result of my observations in this most useful and highly-important branch of our profession. 